\title{
Cellular sources of dysregulated cytokines in relapsing-remitting multiple sclerosis
}

Jeppe Romme Christensen*, Lars Börnsen, Dan Hesse, Martin Krakauer, Per Soelberg Sørensen, Helle Bach Søndergaard and Finn Sellebjerg

\begin{abstract}
Background: Numerous cytokines are implicated in the immunopathogenesis of multiple sclerosis (MS), but studies are often limited to whole blood (WB) or peripheral blood mononuclear cells (PBMCs), thereby omitting important information about the cellular origin of the cytokines. Knowledge about the relation between blood and cerebrospinal fluid (CSF) cell expression of cytokines and the cellular source of CSF cytokines is even more scarce.

Methods: We studied gene expression of a broad panel of cytokines in WB from relapsing-remitting multiple sclerosis (RRMS) patients in remission and healthy controls (HCs). Subsequently we determined the gene expression of the dysregulated cytokines in isolated PBMC subsets (CD4 ${ }^{+}, \mathrm{CD}^{+}{ }^{+}$-cells, NK-cells, B-cells, monocytes and dendritic cells) from RRMS patients and HCs and in CSF-cells from RRMS patients in clinical relapse and noninflammatory neurological controls (NIND).

Results: RRMS patients had increased expression of IFN-gamma (IFNG), interleukin (IL) 1-beta (IL1B), IL7, IL10, IL12A, IL15, IL23, IL27, lymphotoxin-alpha (LTA) and lymphotoxin-beta (LTB) in WB. In PBMC subsets the main sources of pro-inflammatory cytokines were $\mathrm{T}$ - and B-cells, whereas monocytes were the most prominent source of immunoregulatory cytokines. In CSF-cells, RRMS patients had increased expression of IFNG and CD19 and decreased expression of IL10 and CD14 compared to NINDs. CD19 expression correlated with expression of IFNG, IL7, IL12A, IL15 and LTA whereas CD14 expression correlated with IL10 expression.

Conclusions: Using a systematic approach, we show that expression of pro-inflammatory cytokines in peripheral blood primarily originates from T- and B-cells, with an important exception of IFNG which is most strongly expressed by NK-cells. In CSF-cell studies, B-cells appear to be enriched in RRMS and associated with expression of pro-inflammatory cytokines; contrarily, monocytes are relatively scarce in CSF from RRMS patients and are associated with IL10 expression. Thus, our findings suggest a pathogenetic role of B-cells and an immunoregulatory role of monocytes in RRMS.
\end{abstract}

Keywords: Relapsing-remitting multiple sclerosis, Immunology, Cytokines, Blood, Cerebrospinal fluid cells, Real-time $P C R$

\section{Introduction}

Multiple sclerosis (MS) is a chronic, immune-mediated disease of the central nervous system (CNS). An interplay among genetic susceptibility and environmental factors is implicated in the pathogenesis of MS. In relapsing-remitting MS (RRMS), disability develops with relapses. The pathological correlates of clinical relapses

\footnotetext{
* Correspondence: jeppe.romme.christensen@rh.regionh.dk
Department of Neurology, Danish Multiple Sclerosis Center, Copenhagen

* Correspondence: jeppe.romme.christensen@rh.regionh.dk University Hospital Rigshospitalet, Blegdamsvej 9, Copenhagen 2100, Denmark
}

are focal, transient attacks of immune cells on myelin and axons, resulting in the formation of an MS plaque [1]. In pathology studies of brain tissue from RRMS patients, T- and B-cells are seen accumulating in perivascular cuffs near MS plaques and to a lesser extent in the parenchyma, while monocytes and macrophages are seen mostly in the lesion parenchyma. In the cerebrospinal fluid (CSF) many MS patients show a mild pleocytosis. T-cells are the major cell subset in CSF, and compared to non-inflammatory neurological disease (NIND) an increase in B-cells and plasma cells and a 
decrease in monocytes and natural killer (NK) cells is observed in MS patients [2]. The relation between the peripheral immune system and CNS inflammation in RRMS is underscored by the efficacy of treatment with the monoclonal antibodies natalizumab [3] and rituximab [4], which exert their effect on peripheral immune cells, but have a major impact on disease activity, cell numbers, levels of cytokines and markers of tissue damage in CSF [5-7]. During immune attacks on myelin, peripheral activation and subsequent migration of autoreactive T-helper type 1 (Th1) and Th17 cells to the CNS is an essential step [8]. How the T-cells become activated remains unclear, but antigen-presenting cells (APCs) located in peripheral lymph nodes [9] and the subarachnoidal space [10] are likely to be involved.

Gene expression studies of brain tissue, peripheral blood mononuclear cells (PBMCs) and whole blood (WB) from MS patients have shown dysregulated expression of cytokines, chemokines, and transcription factors related to immune activation [11]. Interferon (IFN)-gamma, the Th1 signature cytokine, has been implicated in the pathogenesis of MS, and induced disease activity in a clinical trial [12], although in the animal model experimental autoimmune encephalomyelitis (EAE), Ifng knockout mice developed severe disease [13]. In addition to Th1-cells, Th17-cells that secrete interleukin (IL)-17 are believed to be important in the pathogenesis [8].

Since gene expression studies of molecules used in biomarker studies are mostly carried out on WB or PBMCs, the cellular origin of cytokines is usually not determined. To date, no study has systematically analyzed the cellular origin of dysregulated cytokines in MS patients. Furthermore little is known about cytokine expression in CSF-cells and the cellular source of CSF cytokines. CSF studies are sparse due to the limited availability of CSF, but studies linking peripheral and CSF immune responses are central to understanding the immunopathogenesis of MS, and to translate the many findings in studies of peripheral immune activation.

In the present study, we used gene expression analysis to identify dysregulated cytokines in WB from RRMS patients in clinical remission and subsequently investigated the cellular source of these cytokines in isolated PBMC subsets. Furthermore, to relate the findings in peripheral blood to CNS inflammation, we studied gene expression of the dysregulated cytokines in CSF-cells from RRMS patients in relapse, and determined whether it correlated with markers for T-, B- and NK-cells and monocytes in the CSF.

\section{Materials and methods \\ Subjects}

An initial cohort of 39 untreated RRMS patients in clinical remission and 39 healthy controls (HCs) was recruited for studies of gene expression in WB (Table 1). A second cohort of four untreated RRMS patients in remission and four HCs was recruited for studies of gene expression in isolated PBMC subsets. Finally a third cohort of 17 untreated RRMS patients in relapse and 10 NIND patients (3 with spinal stenosis, 3 with herniated lumbar discs and 4 with low back pain) were recruited for studies on CSF-cells and PBMCs; CSF sampling was done prior to initiation of eventual steroid pulse therapy. All RRMS cohorts studied consisted of both recent onset RRMS and RRMS with longer disease duration (Table 1). The studies were approved by the local scientific ethics committee and informed consent was obtained from all patients and healthy controls.

\section{Gene expression studies}

WB was sampled in PAXgene tubes and RNA extracted using PAXgene Blood RNA Kit (PreAnalytiX, Hombrechtikon, Switzerland); cDNA synthesis was done with High Capacity cDNA Reverse Transcription Kit (Applied Biosystems, Foster City, California, USA). For studies of gene expression in PBMC subsets, PBMCs were isolated using Lymphoprep (Axis-Shield, Oslo, Norway) and subsets of $\mathrm{CD}^{+} \mathrm{T}$-cells, $\mathrm{CD} 8^{+} \mathrm{T}$-cells, NK-cells, B-cells, monocytes and dendritic cells (DC) were isolated using MACS cell separation kits $\left(\mathrm{CD} 4^{+} \mathrm{T}\right.$ Cell Isolation Kit, $\mathrm{CD}^{+} \mathrm{T}$ Cell Isolation Kit, NK Cell Isolation Kit, CD19 MicroBeads, CD14 MicroBeads and Blood Dendritic Cell Isolation Kit) and an autoMACS separator (all from Miltenyi Biotec, Bergisch Gladbach, Germany). Mean purities of the PBMC subsets were above 93\%, except for NK-cells which had a mean purity of $73 \%$. RNA was extracted from 80,000 to 200,000 cells of the obtained subsets with PicoPure RNA Isolation Kit (Arcturus, Mountain View, California, USA). cDNA synthesis was done with qScript cDNA SuperMix (Quanta

Table 1 Demographic and clinical characteristics of the cohorts

\begin{tabular}{|c|c|c|c|c|c|c|}
\hline & \multicolumn{4}{|c|}{ RRMS patients } & \multicolumn{2}{|c|}{ Control groups } \\
\hline & Median age & Female\% & Median EDSS & Duration & Mean age & Female $\%$ \\
\hline Whole blood studies & 34.0 (28.0 to 39.0$)$ & $59 \%$ & 2.0 (1.0 to 3.0$)$ & $5.0(2.0$ to 7.0$)$ & 32.0 (29.0 to 38.0$)$ & $58 \%$ \\
\hline Cell subset studies & 38.0 (30.5 to 47.0$)$ & $75 \%$ & 1.5 (1.0 to 3.1$)$ & $5.0(1.3$ to 12.5$)$ & 33.5 (24.5 to 36.5$)$ & $75 \%$ \\
\hline CSF cell studies & 37.5 (31.3 to 42.8$)$ & $59 \%$ & 3.5 (3.0 to 6.4 ) & $6.0(1.5$ to 9.75$)$ & 51.5 (45.0 to 59.0$)$ & $70 \%$ \\
\hline
\end{tabular}

Median values with interquartile ranges in brackets. EDSS, Expanded Disability Status Scale; RRMS, relapsing-remitting multiple sclerosis. 
BioSciences, Gaithersburg, Maryland, USA). For CSFcell gene expression studies, CSF was obtained by lumbar puncture within 30 days from the onset of a relapse with no evidence of spontaneous recovery. Blood was sampled on the same day as the lumbar puncture and PBMCs were isolated with Lymphoprep. We snap froze at least 5,000 CSF-cells and 200,000 PBMCs for later RNA extraction with PicoPure RNA Isolation Kit and cDNA synthesis with High Capacity cDNA Reverse Transcription Kit.

In the selection of the genes of interest (Table 2), we focused on genes that have been shown to be involved in the pathogenesis of MS, genes involved in the expression of Th1 and Th17 cytokines, and genes expressed in APCs. In a pilot study in the WB cohort we excluded IL1A, IL2, IL4, IL5, IL6, IL9, IL12B, IL13, IL17A, IL17F, IL21, IL33, GM-CSF and BDNF from analysis as candidate biomarkers due to low expression levels in WB samples. Real-time polymerase chain reactions (RT-PCR) were performed with TaqMan Gene Expression Assays on a 7500 Real-Time PCR System (Applied Biosystems, USA). Threshold cycle (CT) values were calculated using SDS software (Applied Biosystems, USA). In CSF-cell samples without amplification the expression value was arbitrarily set to 0 . The relative mRNA transcript expression was calculated by the comparative CT method also referred to as the $2^{-\Delta \Delta C T}$ method, using GAPDH as reference gene. Expression values were normalized to a HC PBMC cDNA pool resulting in a normalization ratio $(\mathrm{NR})$ :

$$
N R=2^{-\triangle \Delta C T},
$$

where

$$
\begin{aligned}
\Delta \Delta C T= & \left(C T_{\text {target } / \text { sample }}-C T_{\text {target } / \text { pool }}\right) \\
& -\left(C T_{G A P D H / \text { sample }}-C T_{G A P D H / \text { pool }}\right)
\end{aligned}
$$

\section{Statistical analysis}

Statistical analysis was performed using PASW 18 software (IBM, Armonk, New York, USA). For comparison between independent groups, non-parametric MannWhitney tests were used. Wilcoxon signed rank tests were used for analysis of paired samples. For correlation analysis, we used Spearman's rank correlation coefficient. Changes in the expression of mRNA were considered significant for $P<0.05$. Since the analysis of gene expression data involved multiple comparisons, we also used the false discovery rate (FDR) method to calculate q-values

\begin{tabular}{|c|c|c|c|c|c|}
\hline Gene Symbol & Assay number & GenBank & Whole blood & PBMC populations & CSF cells \\
\hline GAPDH & Hs99999905_m1 & NM_002046 & . & . & . \\
\hline IFNG & Hs99999041_m1 & NM_000619 & . & . & . \\
\hline$I L 1 B$ & Hs00174097_m1 & NM_000576 & . & . & . \\
\hline ILIRN & Hs00277299_m1 & NM_000577 & . & & \\
\hline IL7 & Hs00174202_m1 & NM_000880 & . & . & . \\
\hline IL10 & Hs00174086_m1 & NM_000572 & & . & . \\
\hline IL12A & Hs00168405_m1 & NM_000882 & . & . & . \\
\hline IL15 & Hs00542571_m1 & NM_172175 & . & . & . \\
\hline IL18 & Hs00155517_m1 & NM_001562 & . & & \\
\hline IL23 & Hs00372324_m1 & NM_016584 & & . & . \\
\hline IL27 & Hs00377366_m1 & NM_145659 & . & . & . \\
\hline$E B I 3$ & Hs00194957_m1 & NM_005755 & . & & \\
\hline LTA & Hs00236874_m1 & NM_000595 & . & . & . \\
\hline$L T B$ & Hs00242739_m1 & NM_009588 & . & . & . \\
\hline TGFB1 & Hs99999918_m1 & NM_000660 & . & & \\
\hline$T N F$ & Hs00174128_m1 & NM_000594 & . & & \\
\hline PRF1 & Hs00169473_m1 & NM_005041 & . & & \\
\hline$C D 3 d$ & Hs00174158_m1 & NM_000732 & & . & . \\
\hline$C D 14$ & Hs00169122_g1 & NM_000591 & & . & . \\
\hline CD19 & Hs01047407_m1 & NM_001770 & & . & . \\
\hline CD56 & Hs00941824_m1 & NM_181351 & & . & . \\
\hline
\end{tabular}
[14]. Q-values were considered significant for $\mathrm{q}<0.05$.

Table 2 List of TaqMan Gene Expression Assays used in the gene expression studies 

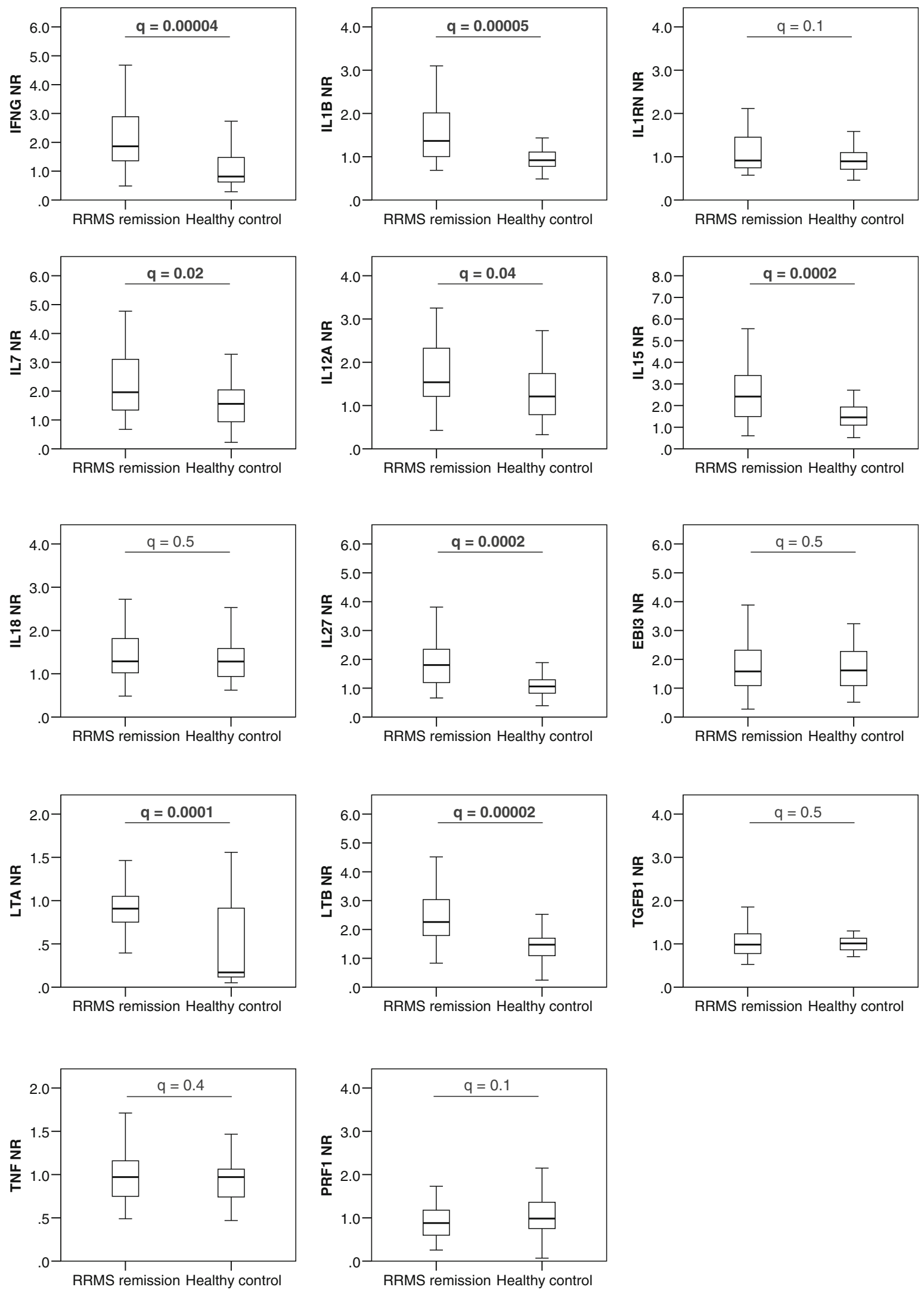

Figure 1 (See legend on next page.) 


\section{Results}

\section{Gene expression in whole blood from RRMS patients in remission}

Initially, we compared the WB expression of cytokine genes in RRMS patients in remission and HCs. We found significantly increased expression of IFN-gamma (IFNG), IL1B, IL7, IL12A, IL15, IL27, lymphotoxin-alpha (LTA) and lymphotoxin-beta (LTB) in RRMS (Figure 1). In previous studies conducted in the same cohort we found increased expression of IL10 and IL23 [15].

\section{Gene expression in PBMC cell subpopulations from RRMS patients in remission}

To substantiate the findings of increased cytokine gene expression in WB from RRMS patients in remission, we conducted gene expression studies on PBMC subsets from four RRMS patients in remission and four HCs. Due to the low number of subjects, we did not expect to find differences between the two groups. As shown in Figure 2, the cellular sources of IFNG are mainly NKcells, $\mathrm{CD}^{+} \mathrm{T}$-cells and, to a lesser extent, CD4 ${ }^{+} \mathrm{T}$-cells. This is not unexpected, but highlights NK-cells as a major source of IFNG and thus questions the use of IFNG as a specific Th1 biomarker in peripheral blood studies without detailing the cellular source. For $I L 1 B$, the cellular sources are mainly monocytes and DCs. Notably, $I L 1 B$ expression in WB is higher than in PBMCs, reflecting that granulocytes are a major source of $I L 1 B$ in WB. IL10 is expressed in monocytes, CD4 ${ }^{+}$ and $\mathrm{CD}^{+} \mathrm{T}$-cells. $I L 7$ and $I L 12 A$ are expressed mainly in B-cells and IL15 mainly in B-cells and monocytes. For IL23, the cellular sources are $\mathrm{CD}^{+}{ }^{+} \mathrm{T}$-cells, $\mathrm{CD} 8^{+} \mathrm{T}$-cells and B-cells. Unexpectedly, we observed low expression in monocytes and DCs. This finding contradicts the current understanding of IL23, which is thought to be an APC cytokine. However, since IL23A transcripts are translated into IL23p19 protein, which together with IL12p40 form bioactive IL23, and IL12p40 production is known to be limited to activated monocytes and DCs [16] and B-cells [17], the biological role of IL23 expression in T-cells is unclear. Thus, our findings indicate that in vivo WB IL23 gene expression is not suitable for studying IL23, which should instead be studied at the protein level as IL-23 p19/IL-12 p40 heterodimer. IL27 expression is restricted to monocytes. LTA is mainly expressed in $\mathrm{CD}^{+}{ }^{+} \mathrm{T}$-cells, $\mathrm{CD} 8^{+} \mathrm{T}$-cells and B-cells and, to a lesser extent, in NK-cells while $L T B$ is mainly expressed in B-cells, CD4 ${ }^{+} \mathrm{T}$-cells and at lower levels in CD8 ${ }^{+} \mathrm{T}$-cells.

\section{Gene expression in PBMCs and CSF-cells from RRMS relapse patients}

Next, we wanted to relate the findings of dysregulated cytokines in peripheral blood cells with CNS inflammation. We analyzed the cytokine expression in CSF-cells and PBMCs from a cohort of RRMS relapsed and NIND patients (Table 3). IL10 expression was significantly enriched in CSF-cells compared to PBMCs with a 9-fold increase in RRMS relapse patients and a 42-fold increase in NINDs. LTB expression was higher in CSF-cells than in PBMCs with a 2.4-fold increase in RRMS relapsed patients and a 1.7-fold increase in NINDs. IL1B expression in CSF-cells was 0.18-fold lower than in PBMCs in RRMS relapsed patients. Compared with NIND, RRMS patients had increased IFNG and decreased IL10 expression in CSF-cells. The IFNG and LTA CSF/PBMC ratios were significantly higher in RRMS relapsed patients, while the IL10 CSF/PBMC ratio was lower in RRMS than in NIND patients. In CSF-cells IL7 and IL15 expression was only detectable in a few samples (all from RRMS patients).

\section{CSF-cell subsets and cytokine gene expression in RRMS relapse patients}

To elucidate whether differences in cytokine gene expression are associated with the cell subsets present in CSF, we analysed gene expression of CD3d, CD14, CD19 and CD56 (markers of T-cells, monocytes, B-cells and NK-cells and NK T-cells, respectively) in CSF-cells (Table 4). Comparing expression of cell type markers in CSF-cells to PBMCs, we found significantly increased expression of CD3d in CSF-cells in RRMS relapse patients and increased CD14 expression in CSF-cells from NINDs. RRMS relapse patients had a decrease in the expression of $C D 14$ and the CD14 CSF/PBMC ratio and an increase in expression of CD19 and the CD19 CSF/PBMC ratio compared with NIND patients.

Correlations between CSF cytokine expression and cell type markers were analyzed using Spearman's rank correlation analysis. Since several of the gene targets were only expressed in some patients, resulting in low statistical power, we analyzed correlations for the whole cohort and for the cohort of RRMS patients in relapse (Table 5). For the whole cohort, INFG and CD19 

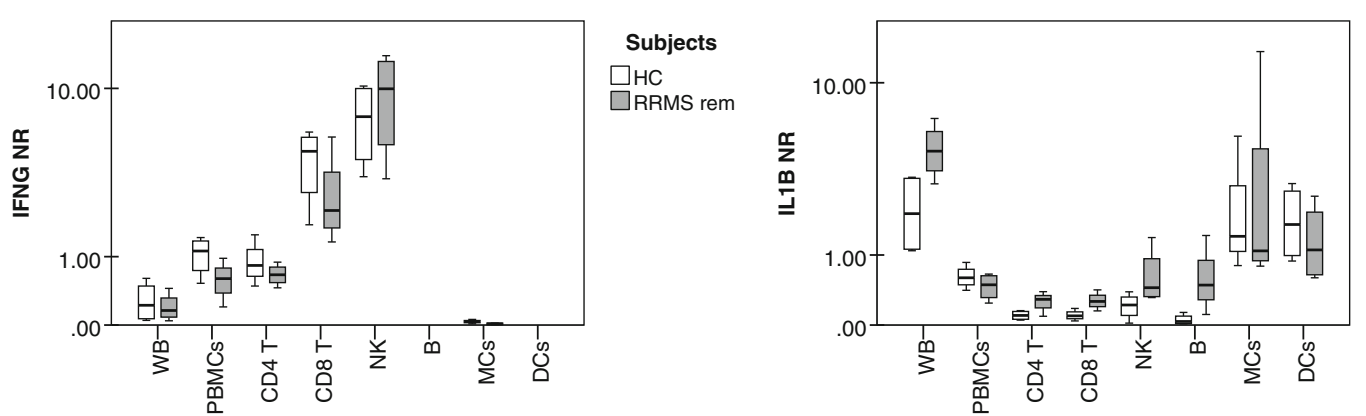

Subjects

$\square \mathrm{HC}$

$\square$ RRMS rem
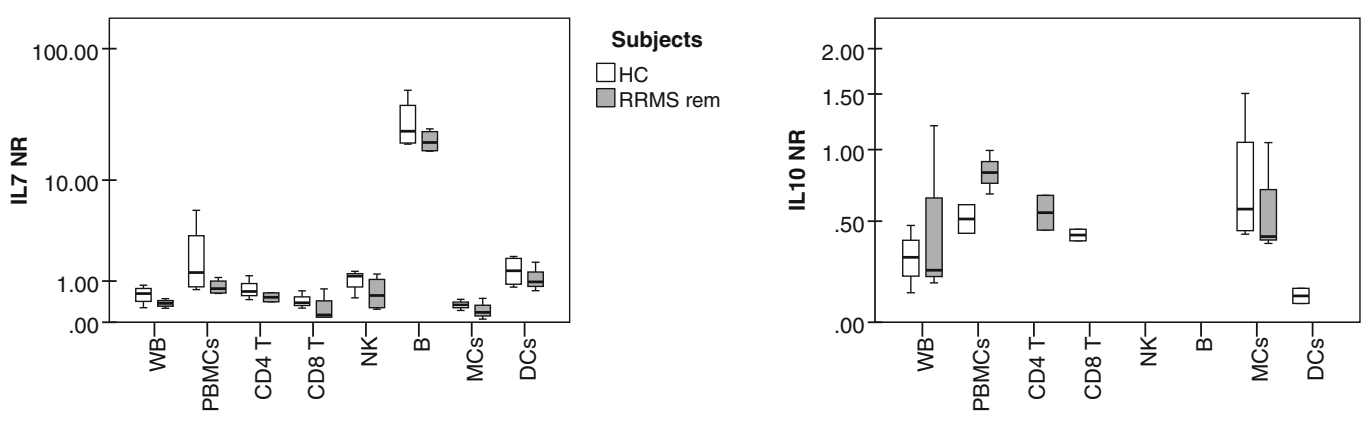

Subjects

$\square \mathrm{HC}$

$\square$ RRMS rem
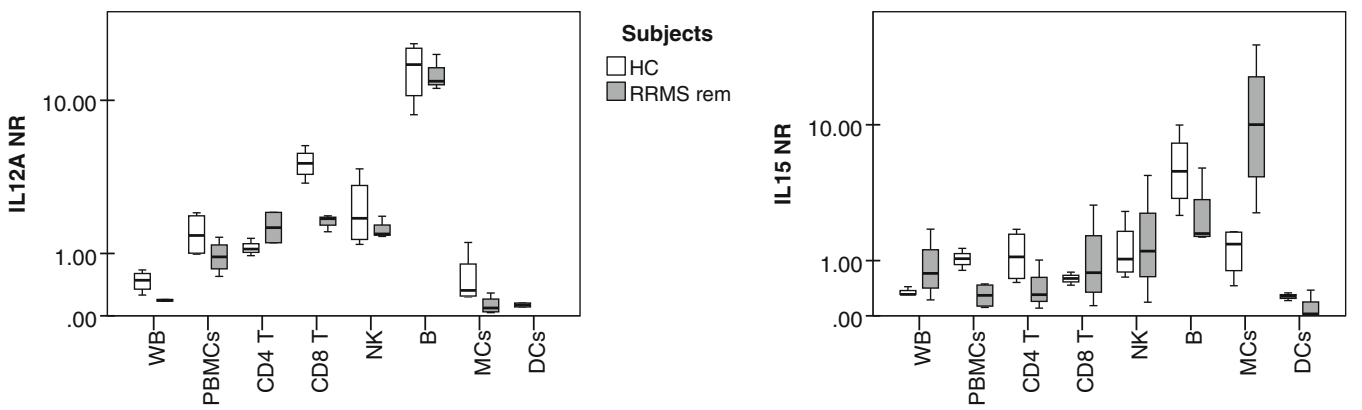

Subjects

$\square \mathrm{HC}$

$\square$ RRMS rem

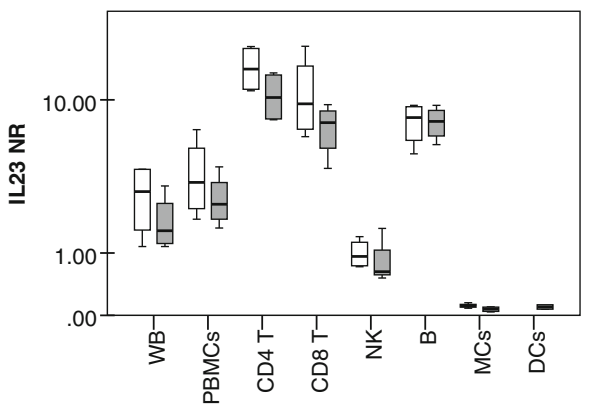

Subjects

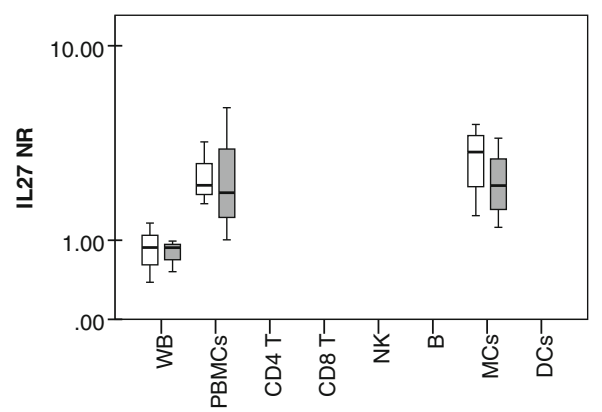

Subjects

$\square$ HC
$\square$ RRMS rem
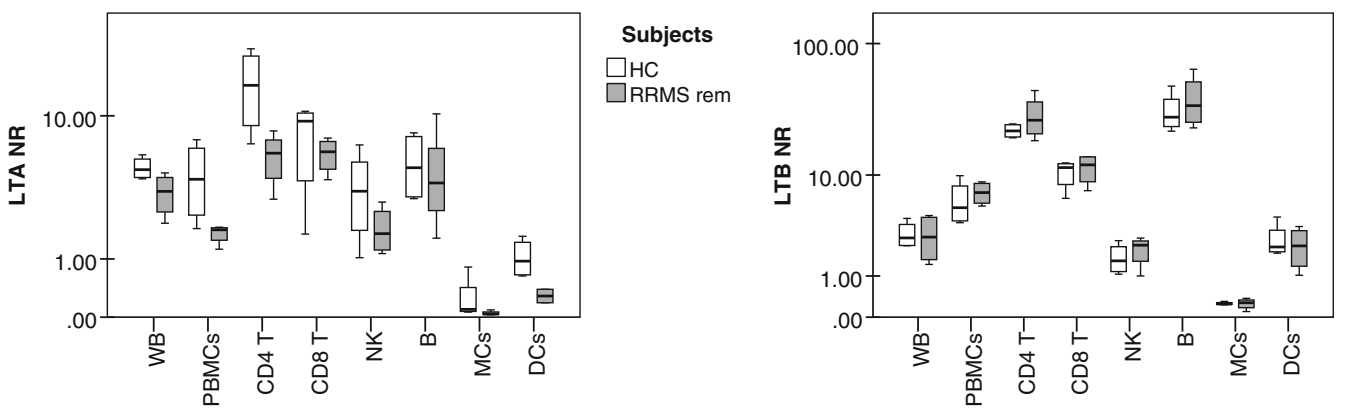

Subjects

$\square \mathrm{HC}$

$\square$ RRMS rem

Figure 2 (See legend on next page.) 
(See figure on previous page.)

Figure 2 Sources of cytokines in peripheral blood cell subsets. Box-plots of cytokine gene expression for different cell populations are isolated from relapsing-remitting patients in remission (RRMS rem) and healthy controls (HC). Gene expression data are shown as the normalization ratio (NR)

expression correlated positively, and INFG and CD14 expression correlated negatively. IL10 expression correlated positively with $C D 14$ and negatively with $C D 19$. IL10 expression in CSF-cells correlated significantly with CD14 expression, suggesting that monocytes are an important source of IL10 in CSF-cells. Consistent with the PBMC subset findings, we further found positive correlations between CD19 and IFNG, IL7, IL12A, IL15 and LTA; CD3d and LTB; CD56 and IL12A. These findings also reached statistical significance when FDR-

Table 3 Cytokine expression in cerebrospinal fluid cells and peripheral blood mononuclear cells

\begin{tabular}{|c|c|c|c|c|c|c|c|c|c|}
\hline & & & RRMS relapse & & & NIND & & RRMS rel & vs NIND \\
\hline & $\begin{array}{c}\text { Mean } \mathrm{CT} \\
\text { value }\end{array}$ & $\mathbf{N}$ & Median (IQR) & $\begin{array}{c}\text { CSF/PBMC } \\
\text { p-value }\end{array}$ & $\mathbf{N}$ & Median (IQR) & $\begin{array}{c}\text { CSF/PBMC } \\
\text { p-value }\end{array}$ & p-value & q-value \\
\hline IFNG PBMC NR & 32.3 & 15 & $4.10(2.74$ to 10.21$)$ & & 10 & 5.25 (2.65 to 9.12$)$ & & 0.78 & 0.37 \\
\hline IFNG CSF NR & 34.9 & 15 & 7.22 (0.00 to 16.42$)$ & & 10 & $0.00(0.00$ to 0.00$)$ & & 0.004 & 0.02 \\
\hline IFNG CSF/PBMC Ratio & & 15 & 0.71 (0.00 to 2.31) & 0.87 & 10 & $0.00(0.00$ to 0.00$)$ & & 0.004 & 0.02 \\
\hline IL1B PBMC NR & 32.4 & 16 & 1.13 (0.88 to 2.14 ) & & 10 & 1.81 (1.05 to 2.70$)$ & & 0.19 & 0.15 \\
\hline IL1B CSF NR & 36.7 & 14 & 0.21 (0.00 to 1.09 ) & & 10 & 2.70 (0.00 to 6.94$)$ & & 0.36 & 0.23 \\
\hline IL1B CSF/PBMC Ratio & & 13 & 0.18 (0.00 to 0.92$)$ & 0.02 & 10 & $1.96(0.00$ to 6.40$)$ & 0.29 & 0.42 & 0.24 \\
\hline IL7 PBMC NR & 34.0 & 16 & 0.41 (0.21 to 1.17 ) & & 10 & 0.31 (0.18 to 0.46$)$ & & 0.40 & 0.24 \\
\hline IL7 CSF NR & 36.1 & 13 & 0.00 (0.00 to 0.86$)$ & & 10 & 0.00 (0.00 to 0.00$)$ & & 0.06 & 0.09 \\
\hline IL7 CSF/PBMC Ratio & & 12 & 0.00 (0.00 to 2.51$)$ & & 8 & $0.00(0.00-0.00)$ & & 0.08 & 0.09 \\
\hline IL10 PBMC NR & 34.3 & 16 & 2.75 (2.02 to 3.90$)$ & & 10 & 2.95 (2.38 to 4.26$)$ & & 0.54 & 0.27 \\
\hline IL10 CSF NR & 35.3 & 17 & 23.51 (3.22 to 46.39$)$ & & 10 & 116.78 (72.22 to 156.28$)$ & & 0.001 & 0.01 \\
\hline IL10 CSF/PBMC Ratio & & 16 & 8.57 (0.79 to 12.71$)$ & 0.003 & 10 & 42.21 (24.04 to 66.18) & 0.01 & 0.002 & 0.01 \\
\hline IL12A PBMC NR & 37.5 & 16 & 0.49 (0.30 to 0.66$)$ & & 10 & 0.54 (0.42 to 0.82$)$ & & 0.53 & 0.27 \\
\hline IL12A CSF NR & 38.3 & 15 & $0.00(0.00$ to 0.00$)$ & & 10 & $0.00(0.00$ to 0.00$)$ & & 0.24 & 0.17 \\
\hline IL12A CSF/PBMC Ratio & & 12 & $0.00(0.00$ to 0.00$)$ & & 9 & $0.00(0.00$ to 0.00$)$ & & 0.21 & 0.16 \\
\hline IL15 PBMC NR & 36.3 & 16 & 1.19 (0.91 to 1.43$)$ & & 10 & 1.10 (0.57 to 1.60$)$ & & 0.79 & 0.37 \\
\hline IL15 CSF NR & 37.3 & 14 & 0.00 (0.00 to 1.10$)$ & & 10 & $0.00(0.00$ to 0.00$)$ & & 0.07 & 0.09 \\
\hline IL15 CSF/PBMC Ratio & & 13 & 0.00 (0.00 to 0.97$)$ & & 10 & $0.00(0.00$ to 0.00$)$ & & 0.06 & 0.09 \\
\hline IL23 PBMC NR & 34.6 & 16 & 0.80 (0.65 to 1.18$)$ & & 10 & 0.80 (0.62 to 1.15$)$ & & 1.00 & 0.44 \\
\hline IL23 CSF NR & 36.8 & 14 & 1.12 (0.00 to 1.98$)$ & & 10 & 0.00 (0.00 to 0.48$)$ & & 0.10 & 0.10 \\
\hline IL23 CSF/PBMC Ratio & & 13 & 1.54 (0.00 to 3.17$)$ & 0.28 & 10 & 0.00 (0.00 to 1.50$)$ & & 0.09 & 0.10 \\
\hline IL27 PBMC NR & 35.1 & 16 & 4.74 (2.49 to 7.60$)$ & & 10 & 8.36 (6.17 to 12.70$)$ & & 0.045 & 0.09 \\
\hline IL27 CSF NR & ND & 14 & 0.00 (0.00 to 0.00$)$ & & 10 & 0.00 (0.00 to 0.00$)$ & & 1.00 & 0.44 \\
\hline IL27 CSF/PBMC Ratio & & 12 & 0.00 (0.00 to 0.00$)$ & & 10 & $0.00(0.00$ to 0.00$)$ & & 1.00 & 0.44 \\
\hline LTA PBMC NR & 34.3 & 16 & 1.74 (1.43 to 2.30$)$ & & 10 & 2.11 (1.59 to 2.73 ) & & 0.37 & 0.23 \\
\hline LTA CSF NR & 36.7 & 14 & 1.41 (0.00 to 3.20$)$ & & 10 & $0.00(0.00$ to 0.00$)$ & & 0.05 & 0.09 \\
\hline LTA CSF/PBMC Ratio & & 13 & 1.08 (0.00 to 1.82$)$ & 0.92 & 10 & $0.00(0.00$ to 0.00$)$ & & 0.04 & 0.09 \\
\hline LTB PBMC NR & 28.2 & 16 & 4.09 (2.44 to 4.99$)$ & & 10 & 3.71 (3.06 to 5.54$)$ & & 0.79 & 0.37 \\
\hline LTB CSF NR & 33.5 & 13 & 8.05 (6.62 to 13.37$)$ & & 10 & 8.82 (3.30 to 12.27 ) & & 0.42 & 0.23 \\
\hline LTB CSF/PBMC Ratio & & 12 & 2.37 (1.76 to 3.12 ) & 0.002 & 10 & 1.70 (0.97 to 3.12$)$ & 0.04 & 0.13 & 0.11 \\
\hline
\end{tabular}

Gene expression data are shown as the normalization ratio (NR). Mean cycle threshold (CT) is shown for each target. CSF/PBMC ratio represent fold change in expression between CSF cells and PBMCs. CSF/PBMC $P$-values represents Wilcoxon signed rank test results, and tests were only conducted if median CSF NR was $>0$. All other $P$-values represent Mann-Whitney tests for differences between groups, and q-values represent false discovery rate corrected $P$-values. Significant test-values are in bold. CSF, cerebrospinal fluid; IQR, Interquartile range; NIND, non-inflammatory neurological disease; PBMC; peripheral blood mononuclear cell; RRMS relapse, relapsing-remitting multiple sclerosis patients in relapse. 
Table 4 Expression of markers of cell types in cerebrospinal fluid cells and peripheral blood mononuclear cells

\begin{tabular}{|c|c|c|c|c|c|c|c|c|c|}
\hline & \multirow[b]{2}{*}{ Mean CT } & \multicolumn{3}{|c|}{ RRMS relapse } & \multicolumn{3}{|c|}{ NIND } & \multicolumn{2}{|c|}{ RRMS relapse vs NIND } \\
\hline & & $\mathbf{N}$ & Median (IQR) & $\begin{array}{c}\text { CSF/PBMC } \\
\text { p-value }\end{array}$ & $\mathbf{N}$ & Median (IQR) & $\begin{array}{c}\text { CSF/PBMC } \\
\text { p-value }\end{array}$ & p-value & q-value \\
\hline CD3d PBMC NR & 31.1 & 15 & 0.06 (0.04 to 0.08$)$ & & 10 & 0.05 (0.04 to 0.07$)$ & & 0.47 & 0.26 \\
\hline CD3d CSF NR & 35.6 & 13 & 0.10 (0.08 to 0.23$)$ & & 10 & 0.06 (0.02 to 0.15$)$ & & 0.07 & 0.09 \\
\hline CD3d CSF/PBMC Ratio & & 11 & 2.37 (1.30 to 3.67$)$ & 0.01 & 10 & 1.12 (0.42 to 3.07$)$ & 0.39 & 0.23 & 0.17 \\
\hline CD14 PBMC NR & 30.1 & 15 & 0.33 (0.27 to 0.38$)$ & & 10 & 0.33 (0.29 to 0.49$)$ & & 0.38 & 0.23 \\
\hline CD14 CSF NR & 34.9 & 13 & 0.38 (0.07 to 0.52$)$ & & 10 & 1.52 (0.94 to 2.40$)$ & & 0.0004 & 0.01 \\
\hline CD14 CSF/PBMC Ratio & & 11 & 1.39 (0.30 to 2.15$)$ & 0.42 & 10 & 4.01 (3.54 to 5.16$)$ & 0.01 & 0.003 & 0.02 \\
\hline CD19 PBMC NR & 36.1 & 15 & 0.14 (0.09 to 0.23 ) & & 10 & 0.08 (0.05 to 0.16$)$ & & 0.05 & 0.09 \\
\hline CD19 CSF NR & 37.1 & 13 & 0.00 (0.00 to 0.35$)$ & & 10 & $0.00(0.00$ to 0.00$)$ & & 0.03 & 0.09 \\
\hline CD19 CSF/PBMC Ratio & & 11 & $0.00(0.00$ to 0.89$)$ & & 10 & $0.00(0.00$ to 0.00$)$ & & 0.04 & 0.09 \\
\hline CD56 PBMC NR & 34.9 & 15 & 0.15 (0.09 to 0.23 ) & & 10 & 0.16 (0.07 to 0.32$)$ & & 0.96 & 0.43 \\
\hline CD56 CSF NR & 37.8 & 13 & 0.00 (0.00 to 0.03$)$ & & 10 & 0.00 (0.00 to 0.00$)$ & & 0.11 & 0.10 \\
\hline CD56 CSF/PBMC Ratio & & 11 & $0.00(0.00$ to 0.00$)$ & & 10 & 0.00 (0.00 to 0.00$)$ & & 0.17 & 0.14 \\
\hline
\end{tabular}

Gene expression data are shown as normalization ratio (NR). Mean cycle threshold (CT) is shown for each target. CSF/PBMC ratio represent fold change in expression between CSF cells and PBMCs. CSF/PBMC p-values represents Wilcoxon signed rank test results, and tests were only conducted if median CSF NR was $>0$. All other $p$-values represent Mann-Whitney tests for difference between groups, and q-values represent false discovery rate corrected $p$-values. Significant test-values are in bold. RRMS relapse: Relapsing-remitting multiple sclerosis patients in relapse. NIND: Non-inflammatory neurological disease. PBMC: Peripheral blood mononuclear cell. CSF: Cerebrospinal fluid. IQR: Interquartile range.

corrected q-values were calculated. For RRMS relapse patients some of the correlations were confirmed, but none of them reached statistical significance when qvalues were calculated.

\section{Discussion}

In the present study we find an increased expression of pro-inflammatory (INFG, IL1B, IL7, IL12A, IL15, IL23, $L T A$ and $L T B$ ) and immunoregulatory cytokines (IL10 and IL27) in WB from RRMS patients in remission. In subsequent gene expression studies on PBMC subsets, our findings confirm the expected sources for many cytokines, but for others we reveal unexpected cell-types to be major sources. In general, $\mathrm{T}$ - and B-cells are the most frequent sources of the pro-inflammatory cytokines, and monocytes are the predominant source of the immunoregulatory cytokines. In CSF-cell studies, we demonstrate that the majority of the cytokines are expressed by CSF-cells, and that CSF-cells from RRMS patients have increased expression of IFNG and markers of T- and B-cells, whereas IL1O and the marker for monocytes have decreased expression. Finally, the B-cell marker CD19 correlated positively with many proinflammatory cytokines in CSF-cells.

We present a systematic approach to determine the cellular source of dysregulated cytokines in RRMS, which is critical in the interpretation of findings in cytokine biology. Our studies addressed the expression of genes that may serve as biomarkers of fundamental pathogenic processes in MS in fresh blood samples, which allows studying cytokine biology close to in vivo conditions, without the need for in vitro stimulation. However, in vivo studies have limitations, since they do not address the full potential for activation of the cells in the same way that in vitro studies do. Furthermore, gene expression does not necessarily result in translation into bioactive protein, and post-translational modifications or regulated secretion are not reflected by mRNA expression studies. The studies on isolated cell-subsets were generally performed on samples with high purity, but for NK-cells the purity was $73 \%$ on average. This could represent a potential bias, as genes not normally detected in NK-cells possibly will be detected. Thus, for genes with low expression levels in NK-cells, conclusions must be very cautious. On the other hand, the very high expression of IFNG by NK-cells is not likely to be a result of this impurity. The CSF-cell study had limited statistical power due to the relatively low number of subjects and the low amount of mRNA that could be extracted from these cells. This implies that more target molecules might have been detected if more mRNA had been available. Caution is therefore important in the interpretation of differences in expression levels between PBMCs and CSF-cells in MS patients and controls. Not only will differences in the cellular composition of CSF samples in MS patients and neurological controls confound the results obtained, but differences in the composition of blood and CSF-cell populations common to patients and controls should also be taken into account. Adding to this, specific cell-subsets might change their phenotype or gene expression patterns upon crossing the blood-brainbarrier [18,19]. 
Table 5 Correlations between cytokine and cell type marker expression in cerebrospinal fluid cells

\begin{tabular}{|c|c|c|c|c|c|c|c|c|c|c|}
\hline \multirow{2}{*}{\multicolumn{3}{|c|}{ CSF NR }} & \multicolumn{4}{|c|}{ RRMS relapse and NIND } & \multicolumn{4}{|c|}{ RRMS relapse } \\
\hline & & & $\mathbf{N}$ & $\mathbf{R}$ & p-value & q-value & $\mathbf{N}$ & $\mathbf{R}$ & p-value & q-value \\
\hline IFNG & vs & $C D 3 d$ & 22 & 0.383 & 0.08 & 0.06 & 12 & 0.441 & 0.151 & 0.39 \\
\hline IFNG & vs & $C D 14$ & 22 & -0.606 & 0.003 & 0.008 & 12 & 0.018 & 0.956 & 0.90 \\
\hline IFNG & vs & $C D 19$ & 22 & 0.538 & 0.010 & 0.02 & 12 & 0.111 & 0.731 & 1.04 \\
\hline IFNG & vs & CD56 & 22 & 0.372 & 0.09 & 0.06 & 12 & 0.019 & 0.954 & 0.93 \\
\hline ILIB & vs & $C D 3 d$ & 23 & -0.453 & 0.03 & 0.03 & 13 & 0.064 & 0.837 & 0.89 \\
\hline ILIB & vs & $C D 14$ & 23 & 0.126 & 0.57 & 0.27 & 13 & 0.067 & 0.829 & 0.91 \\
\hline ILIB & vs & $C D 19$ & 23 & 0.168 & 0.44 & 0.21 & 13 & 0.435 & 0.137 & 0.39 \\
\hline ILIB & vs & $C D 56$ & 23 & 0.110 & 0.62 & 0.28 & 13 & 0.285 & 0.345 & 0.73 \\
\hline IL7 & vs & $C D 3 d$ & 23 & 0.090 & 0.68 & 0.30 & 13 & -0.121 & 0.694 & 1.03 \\
\hline IL7 & vs & $C D 14$ & 23 & -0.169 & 0.44 & 0.22 & 13 & 0.087 & 0.777 & 0.98 \\
\hline IL7 & vs & $C D 19$ & 23 & 0.600 & 0.002 & 0.009 & 13 & 0.513 & 0.073 & 0.36 \\
\hline IL7 & vs & $C D 56$ & 23 & 0.412 & 0.05 & 0.04 & 13 & 0.241 & 0.429 & 0.86 \\
\hline IL10 & vs & $C D 3 d$ & 23 & -0.506 & 0.01 & 0.02 & 13 & -0.589 & 0.034 & 0.23 \\
\hline IL10 & vs & $C D 14$ & 23 & 0.773 & 0.00002 & 0.00011 & 13 & 0.541 & 0.056 & 0.32 \\
\hline IL10 & vs & CD19 & 23 & -0.438 & 0.04 & 0.04 & 13 & -0.151 & 0.623 & 1.01 \\
\hline IL10 & vs & $C D 56$ & 23 & -0.242 & 0.27 & 0.15 & 13 & 0.086 & 0.781 & 0.95 \\
\hline IL12A & vs & $C D 3 d$ & 23 & 0.075 & 0.73 & 0.31 & 13 & -0.096 & 0.755 & 1.03 \\
\hline IL12A & vs & CD14 & 23 & -0.327 & 0.13 & 0.08 & 13 & -0.236 & 0.437 & 0.78 \\
\hline IL12A & vs & $C D 19$ & 23 & 0.577 & 0.004 & 0.008 & 13 & 0.508 & 0.076 & 0.32 \\
\hline IL12A & vs & CD56 & 23 & 0.756 & 0.00003 & 0.00014 & 13 & 0.697 & 0.008 & 0.09 \\
\hline IL15 & vs & $C D 3 d$ & 23 & 0.226 & 0.30 & 0.16 & 13 & 0.067 & 0.828 & 0.94 \\
\hline IL15 & vs & $C D 14$ & 23 & -0.519 & 0.01 & 0.02 & 13 & -0.450 & 0.123 & 0.42 \\
\hline IL15 & vs & $C D 19$ & 23 & 0.847 & 0.0000003 & 0.0000048 & 13 & 0.758 & 0.003 & 0.09 \\
\hline IL15 & vs & $C D 56$ & 23 & 0.469 & 0.02 & 0.03 & 13 & 0.349 & 0.242 & 0.59 \\
\hline IL23 & vs & $C D 3 d$ & 23 & 0.004 & 0.98 & 0.39 & 13 & 0.034 & 0.912 & 0.91 \\
\hline IL23 & vs & $C D 14$ & 23 & -0.396 & 0.06 & 0.05 & 13 & -0.040 & 0.898 & 0.92 \\
\hline IL23 & vs & $C D 19$ & 23 & 0.340 & 0.11 & 0.07 & 13 & 0.177 & 0.562 & 0.96 \\
\hline IL23 & vs & CD56 & 23 & 0.234 & 0.28 & 0.15 & 13 & 0.092 & 0.766 & 1.00 \\
\hline$L T A$ & vs & $C D 3 d$ & 23 & 0.002 & 0.99 & 0.39 & 13 & -0.121 & 0.693 & 1.07 \\
\hline$L T A$ & vs & $C D 14$ & 23 & -0.420 & 0.05 & 0.04 & 13 & -0.078 & 0.800 & 0.94 \\
\hline LTA & vs & $C D 19$ & 23 & 0.563 & 0.005 & 0.009 & 13 & 0.461 & 0.113 & 0.43 \\
\hline LTA & vs & $C D 56$ & 23 & 0.384 & 0.07 & 0.05 & 13 & 0.238 & 0.433 & 0.82 \\
\hline$L T B$ & vs & $C D 3 d$ & 23 & 0.579 & 0.004 & 0.009 & 13 & 0.440 & 0.133 & 0.41 \\
\hline$L T B$ & vs & $C D 14$ & 23 & -0.057 & 0.80 & 0.33 & 13 & 0.305 & 0.310 & 0.70 \\
\hline LTB & vs & $C D 19$ & 23 & -0.337 & 0.12 & 0.07 & 13 & -0.702 & 0.008 & 0.13 \\
\hline LTB & vs & $C D 56$ & 23 & -0.304 & 0.16 & 0.09 & 13 & -0.598 & 0.031 & 0.26 \\
\hline
\end{tabular}

Gene expression data are shown as the normalization ratio (NR). Correlation analysis was done with Spearman's rank correlation coefficient, and q-values represent the false discovery rate corrected $P$-values. Significant values are in bold. RRMS relapse: Relapsing-remitting multiple sclerosis patients in relapse. CSF cerebrospinal fluid; NIND, Non-inflammatory neurological disease; PBMC, Peripheral blood mononuclear cell.

Looking into the possible roles of specific cytokines found to be dysregulated in our patients with RRMS, IFN-gamma is known to be present in brain lesions in MS patients [20], and IFN-gamma secretion is increased in T-cells from RRMS patients in the blood and even more in CSF. Experimental studies indicate that IFNgamma, at least when expressed by $\mathrm{CD} 4^{+} \mathrm{T}$-cells, has important effects along with IL17 in the development of RRMS [8]. Our findings of increased IFNG in WB and CSF-cells in RRMS patients are in accordance with 
previous studies, but the finding of NK-cells and $\mathrm{CD}^{+} \mathrm{T}$ cells as the major sources highlights that IFNG expression in WB is associated with other cellular responses than Th1. As NK-cells have been attributed an immunoregulatory role in MS, this could explain the known ambiguous effects of IFN-gamma in MS and animal models of MS, and our finding emphasizes that further clarification of the function of IFN-gamma in MS requires studies of NK-cells and CD8 ${ }^{+}$T-cells. The finding of increased IFNG expression in CSF-cells is more likely attributed a proinflammatory role in T-cells, and interestingly correlates with B-cells.

We have previously demonstrated negative correlation between expression of the immunoregulatory cytokine IL1O and the number of active magnetic resonance imaging lesions [21], and IL10 has been suggested to have beneficial effects in MS in numerous studies [22,23]. IL10 is present in perivascular macrophages in MS lesions [24] and is increased in CSF from MS patients [25]. In blood, studies of IL10 expression have been conflicting [25-27] but most biomarker studies point to a slight increase in IL10 gene expression in MS. Accordingly, we find IL10 expression to be increased in WB from RRMS in remission compared to HCs. In CSF-cells we find a decrease in IL10 mRNA expression in RRMS relapse compared to NIND patients. This corresponds to a study showing that IL10-protein is decreased during relapses [28], whereas data from a study on a mixed MS group and a non-inflammatory control group [29], reported increased IL10 mRNA expression in in CSFcells from MS. The latter study used a mixed MS group where the majority was not in relapse, and hence a likely explanation for the conflicting results is the differences in the specific patient groups studied. Finally, since IL10 expression was pronounced in monocytes in our PBMC subset study and correlated negatively with $C D 3 d$ and CD19 and positively with CD14 in CSF-cells, our findings support that monocytes may have an immunoregulatory role in MS. However, the decreased CSF-cell IL10 expression in RRMS compared to NIND patients could also simply reflect a relatively decreased frequency of monocytes in MS patients [2] or a change in the monocyte phenotype, since monocytes transmigrating across the blood-brain barrier change their phenotype [19], and CSF monocytes have decreased CD14 expression $[18,30]$.

IL7 and IL15 are IL-2 family cytokines regulating survival and activation of lymphocytes, and are of interest in MS research since they signal through the IL2- and IL7-receptors, which have shown strong association with MS in genome-wide association studies [31]. Expression of these cytokines is increased in MS brain lesions $[32,33]$, in CSF [34,35] and in blood from MS patients $[36,37]$. The finding of increased WB expression is in accordance with previous studies on blood cells. Since IL7 and IL15 both contribute to increased T-cell survival and Th1 induction, our findings could represent a B-cell and monocyte-driven pro-inflammatory response in the peripheral immune compartment of MS patients. On the other hand IL15 is also essential for NK-cell survival and IL15-deficiency in mice results in worsening of EAE [38], why caution in the interpretation of the IL15 findings should be stressed.

The finding of IL23 expression being most pronounced in T-and B-cells, make clear that a systematic approach can be necessary to derive proper conclusions about the biology behind cytokine gene expression, and in this particular example, that the biological significance of in vivo IL23 expression is unclear and will demand studies of IL23 expression in T-cells.

Lymphotoxin is present in MS lesions [39] and expression is increased in blood and CSF in MS [40,41]. Being important for the crosstalk between APCs and T-cells and for the development of ectopic follicle-like structures seen in MS and other autoimmune diseases [42,43] our finding of increased lymphotoxin in WB and CSFcells points to a probable pro-inflammatory function of this cytokine in MS, although studies proving that the increased mRNA expression is associated with increased bioactivity are needed to substantiate this hypothesis.

\section{Conclusion}

In conclusion, we have confirmed previous findings of dysregulated cytokines in WB in MS patients, particularly increased expression of pro-inflammatory cytokines. A detailed analysis of the cytokine expression in PBMC subsets confirmed the expected origin for some cytokines, while other cytokines also were expressed in unexpected subsets. Most pro-inflammatory cytokines were expressed by B-cells in blood and correlated with CD19 in CSF-cells. Monocytes were the predominant source of immunoregulatory cytokines, and IL10 was decreased in CSF-cells compared to NINDs, and correlated with CD14 in CSF-cells. These findings correspond to studies on CSF-cells in MS $[44,45]$ and a study showing that the most variable cell parameter in CSF is the B-cell/monocyte ratio, which also correlates with disease progression [2]. Thus our study supports a central role of B-cells in the pathogenesis of MS. Recently this has been highlighted by studies proving the benefit of treatment with B cell-depleting antibodies in MS [46].

\section{Abbreviations}

APC: Antigen-presenting cell; CNS: Central nervous system; CSF: Cerebrospinal fluid; CT: Threshold cycle; DC: Dendritic cell;

EAE: Experimental autoimmune encephalomyelitis; EDSS: Expanded Disability Status Scale; FDR: False discovery rate; HC: Healthy controls; IFN: Interferon;

IFNG: Interferon-gamma; IL: Interleukin; LTA: Lymphotoxin-alpha;

LTB: Lymphotoxin-beta; MS: Multiple sclerosis; NIND: Non-Inflammatory neurological disease; NK-cell: Natural killer cell; NR: Normalization ratio; 
PBMC: Peripheral blood mononuclear cell; RRMS: Relapsing-remitting MS; RTPCR: Real-time polymerase chain reactions; Th1: T-helper type 1; Th17: Thelper type 17; WB: Whole blood.

\section{Competing interests}

JRC received honoraria for lecturing from Biogen-Idec. DH has received funding for travel from Biogen Idec, Merck-Serono and Sanofi-Aventis; and received speaker honoraria from Sanofi-Aventis and Biogen Idec. LB, MK and HBS report no disclosures. PSS has served on scientific advisory boards for Biogen Idec, Merck Serono, Novartis, Genmab, TEVA, Elan and GSK; and has been on steering committees or independent data monitoring boards in clinical trials sponsored by Merck Serono, Genmab, TEVA, GSK and Bayer Schering. He has received funding of travel for these activities, has served as Editor-in-Chief of the European Journal of Neurology, and is an editorial board member for Therapeutic Advances in Neurological Disorders and Multiple Sclerosis. He has received speaker honoraria from Biogen Idec, Merck Serono, TEVA, Bayer Schering, Sanofi-aventis, and Novartis. His department has received research support from Biogen Idec, Bayer Schering, Merck Serono, TEVA, Baxter, Sanofi-Aventis, BioMS, Novartis, Bayer, RoFAR, Roche, Genzyme, and from the Danish Multiple Sclerosis Society, the Danish Medical Research Council, and the European Union Sixth Framework Programme: Life Sciences, Genomics and Biotechnology for Health. FS has served on scientific advisory boards for and received funding for travel from Biogen Idec, Merck-Serono, Novartis, Sanofi-Aventis and Teva; and has served as a consultant for Biogen Idec and Novo Nordisk; received speaker honoraria from Bayer-Schering, Biogen Idec, Merck-Serono, Novartis, Sanofi-Aventis and Schering-Ploug. He has received research support from Biogen Idec, Merck-Serono, Novartis and Sanofi-Aventis; and serves as section editor on Multiple Sclerosis and Related Disorders.

\section{Authors' contributions}

JRC, LB, DH, MK, HBS and FS collected the samples, performed the laboratory analyses and analyzed data. JRC and FS wrote the first draft of the manuscript. All authors participated in the interpretation of the data and contributed to the critical review of the manuscript. All authors read and approved the final version of the manuscript.

\section{Acknowledgements}

This work was supported by the Danish Council for Independent Research (grant 271-06-0246), the Danish Council for Strategic Research (grant 214208-0039), the Danish MS Society, the Warwara Larsen Foundation, the Johnsen Foundation, Brdr. Rønje Holding, Jeppe Juel Memorial Legacy and research grants from Biogen Idec, Merck Serono and Novartis.

Received: 4 June 2012 Accepted: 6 September 2012

Published: 14 September 2012

\section{References}

1. Compston A, Coles A: Multiple sclerosis. Lancet 2008, 372:1502-1517.

2. Cepok S, Jacobsen M, Schock S, Omer B, Jaekel S, Boddeker I, Oertel WH, Sommer N, Hemmer B: Patterns of cerebrospinal fluid pathology correlate with disease progression in multiple sclerosis. Brain 2001, 124:2169-2176.

3. Polman $\mathrm{CH}, \mathrm{O}^{\prime}$ Connor PW, Havrdova E, Hutchinson M, Kappos L, Miller DH, Phillips JT, Lublin FD, Giovannoni G, Wajgt A, Toal M, Lynn F, Panzara MA, Sandrock AW, AFFIRM Investigators: A randomized, placebo-controlled trial of natalizumab for relapsing multiple sclerosis. N Engl J Med 2006, 354:899-910.

4. Hauser SL, Waubant E, Arnold DL, Vollmer T, Antel J, Fox RJ, Bar-Or A Panzara M, Sarkar N, Agarwal S, Langer-Gould A, Smith CH, HERMES Trial Group: B-cell depletion with rituximab in relapsing-remitting multiple sclerosis. N Engl J Med 2008, 358:676-688.

5. Khademi M, Bornsen L, Rafatnia F, Andersson M, Brundin L, Piehl F, Sellebjerg F, Olsson T: The effects of natalizumab on inflammatory mediators in multiple sclerosis: prospects for treatment-sensitive biomarkers. Eur J Neurol 2009, 16:528-536.

6. del Pilar Martin M, Cravens PD, Winger R, Frohman EM, Racke MK, Eagar TN, Zamvil SS, Weber MS, Hemmer B, Karandikar NJ, Kleinschmidt-DeMasters BK, Stüve O: Decrease in the numbers of dendritic cells and CD4+ T cells in cerebral perivascular spaces due to natalizumab. Arch Neurol 2008, 65:1596-1603.
7. Cross AH, Stark JL, Lauber J, Ramsbottom MJ, Lyons JA: Rituximab reduces $B$ cells and T cells in cerebrospinal fluid of multiple sclerosis patients. J Neuroimmunol 2006, 180:63-70.

8. Kebir H, Ifergan I, Alvarez JI, Bernard M, Poirier J, Arbour N, Duquette P, Prat A: Preferential recruitment of interferon-gamma-expressing $\mathrm{TH} 17$ cells in multiple sclerosis. Ann Neurol 2009, 66:390-402.

9. Van-Zwam M, Huizinga R, Melief MJ, Wierenga-Wolf AF, Van-Meurs M, Voerman JS, Biber KP, Boddeke HW, Hopken UE, Meisel C, Meisel A, Bechmann I, Hintzen RQ, T-Hart BA, Amor S, Laman JD, Boven LA: Brain antigens in functionally distinct antigen-presenting cell populations in cervical lymph nodes in MS and EAE. J Mol Med (Berl) 2009, 87:273-286.

10. Kivisakk P, Imitola J, Rasmussen S, Elyaman W, Zhu B, Ransohoff RM, Khoury SJ: Localizing central nervous system immune surveillance: meningeal antigen-presenting cells activate $T$ cells during experimental autoimmune encephalomyelitis. Ann Neurol 2009, 65:457-469.

11. Sospedra M, Martin R: Immunology of multiple sclerosis. Annu Rev Immunol 2005, 23:683-747.

12. Panitch HS, Hirsch RL, Haley AS, Johnson KP: Exacerbations of multiple sclerosis in patients treated with gamma interferon. Lancet 1987, 1:893-895.

13. Krakowski M, Owens T: Interferon-gamma confers resistance to experimental allergic encephalomyelitis. Eur J Immunol 1996, 26:1641-1646.

14. Storey JD, Tibshirani R: Statistical significance for genomewide studies. Proc Natl Acad Sci U S A 2003, 100:9440-9445.

15. Krakauer M, Sorensen P, Khademi M, Olsson T, Sellebjerg F: Increased IL-10 mRNA and IL-23 mRNA expression in multiple sclerosis: interferon-beta treatment increases IL-10 mRNA expression while reducing IL-23 mRNA expression. Mult Scler 2008, 14:622-630.

16. Brentano F, Ospelt C, Stanczyk J, Gay RE, Gay S, Kyburz D: Abundant expression of the interleukin (IL)23 subunit p19, but low levels of bioactive IL23 in the rheumatoid synovium: differential expression and Toll-like receptor-(TLR) dependent regulation of the IL23 subunits, p19 and p40, in rheumatoid arthritis. Ann Rheum Dis 2009, 68:143-150.

17. Yeo L, Toellner KM, Salmon M, Filer A, Buckley CD, Raza K, Scheel-Toellner D: Cytokine mRNA profiling identifies B cells as a major source of RANKL in rheumatoid arthritis. Ann Rheum Dis 2011, 70:2022-2028.

18. Salmaggi A, Sandberg-Wollheim M: Monocyte phenotype in blood and cerebrospinal fluid: compartment-specific pattern is unrelated to neurological disease. J Neurol Sci 1993, 120:201-207.

19. Ifergan I, Kebir H, Bernard M, Wosik K, Dodelet-Devillers A, Cayrol R, Arbour $\mathrm{N}$, Prat $A$ : The blood-brain barrier induces differentiation of migrating monocytes into Th17-polarizing dendritic cells. Brain 2008, 131:785-799.

20. Cannella B, Raine CS: The adhesion molecule and cytokine profile of multiple sclerosis lesions. Ann Neurol 1995, 37:424-435.

21. Hesse D, Krakauer M, Lund H, Sondergaard HB, Limborg SJ, Sorensen PS, Sellebjerg F: Disease protection and interleukin-10 induction by endogenous interferon-beta in multiple sclerosis? Eur J Neurol 2011, 18:266-272.

22. Cucci A, Barbero P, Clerico M, Ferrero B, Versino E, Contessa G, Demercanti S, Viglietta E, Di Liberto A, Vai AG, Durelli L: Pro-inflammatory cytokine and chemokine mRNA blood level in multiple sclerosis is related to treatment response and interferon-beta dose. J Neuroimmunol 2010, 226:150-157.

23. Calabresi PA, Tranquill LR, McFarland HF, Cowan EP: Cytokine gene expression in cells derived from CSF of multiple sclerosis patients. J Neuroimmunol 1998, 89:198-205.

24. Hulshof S, Montagne L, De Groot CJ, Van Der Valk P: Cellular localization and expression patterns of interleukin-10, interleukin-4, and their receptors in multiple sclerosis lesions. Glia 2002, 38:24-35.

25. Navikas $V$, Link J, Palasik W, Soderstrom M, Fredrikson S, Olsson T, Link H: Increased mRNA expression of IL-10 in mononuclear cells in multiple sclerosis and optic neuritis. Scand J Immunol 1995, 41:171-178.

26. Ozenci V, Kouwenhoven M, Huang YM, Kivisakk P, Link H: Multiple sclerosis is associated with an imbalance between tumour necrosis factor-alpha (TNF-alpha)- and IL-10-secreting blood cells that is corrected by interferon-beta (IFN-beta) treatment. Clin Exp Immunol 2000, 120:147-153.

27. Ozenci V, Kouwenhoven M, Huang YM, Xiao B, Kivisakk P, Fredrikson S, Link $H$ : Multiple sclerosis: levels of interleukin-10-secreting blood mononuclear cells are low in untreated patients but augmented during interferon-beta-1b treatment. Scand J Immunol 1999, 49:554-561. 
28. Carrieri PB, Provitera V, De Rosa T, Tartaglia G, Gorga F, Perrella O: Profile of cerebrospinal fluid and serum cytokines in patients with relapsingremitting multiple sclerosis: a correlation with clinical activity. Immunopharmacol Immunotoxicol 1998, 20:373-382.

29. Khademi M, Illes Z, Gielen AW, Marta M, Takazawa N, Baecher-Allan C, Brundin L, Hannerz J, Martin C, Harris RA, Hafler DA, Kuchroo VK, Olsson T, Piehl F, Wallström E: T Cell Ig- and mucin-domain-containing molecule-3 (TIM-3) and TIM-1 molecules are differentially expressed on human Th1 and Th2 cells and in cerebrospinal fluid-derived mononuclear cells in multiple sclerosis. J Immunol 2004, 172:7169-7176.

30. lacobaeus E, Amoudruz P, Strom M, Khademi M, Brundin L, Hillert J, Kockum I, Malmström V, Olsson T, Tham E, Piehl F: The expression of VEGF-A is down regulated in peripheral blood mononuclear cells of patients with secondary progressive multiple sclerosis. PLOS One 2011, 6:e19138.

31. International Multiple Sclerosis Genetics Consortium, Wellcome Trust Case Control Consortium 2, Sawcer S, Hellenthal G, Pirinen M, Spencer CC, Patsopoulos NA, Moutsianas L, Dilthey A, Su Z, Freeman C, Hunt SE, Edkins S, Gray E, Booth DR, Potter SC, Goris A, Band G, Oturai AB, Strange A, Saarela J, Bellenguez C, Fontaine B, Gillman M, Hemmer B, Gwilliam R, Zipp F, Jayakumar A, Martin R, Leslie S, Hawkins S, Giannoulatou E, et al: Genetic risk and a primary role for cell-mediated immune mechanisms in multiple sclerosis. Nature 2011, 476:214-219.

32. Kremlev SG, Gaurnier-Hausser AL, Del Valle L, Perez-Liz G, Dimitrov S, Tuszynski G: Angiocidin promotes pro-inflammatory cytokine production and antigen presentation in multiple sclerosis. J Neuroimmunol 2008, 194:132-142.

33. Baranzini SE, Elfstrom C, Chang SY, Butunoi C, Murray R, Higuchi R, Oksenberg JR: Transcriptional analysis of multiple sclerosis brain lesions reveals a complex pattern of cytokine expression. J Immunol 2000, 165:6576-6582.

34. Lundmark F, Duvefelt K, lacobaeus E, Kockum I, Wallstrom E, Khademi M, Oturai A, Ryder LP, Saarela J, Harbo HF, Celius EG, Salter H, Olsson T, Hillert J: Variation in interleukin 7 receptor alpha chain (IL7R) influences risk of multiple sclerosis. Nat Genet 2007, 39:1108-1113.

35. Kivisakk P, Matusevicius D, He B, Soderstrom M, Fredrikson S, Link H: IL-15 mRNA expression is up-regulated in blood and cerebrospinal fluid mononuclear cells in multiple sclerosis (MS). Clin Exp Immunol 1998, 111:193-197.

36. Lee LF, Axtell R, Tu GH, Logronio K, Dilley J, Yu J, Rickert M, Han B, Evering W, Walker MG, Shi J, de Jong BA, Killestein J, Polman CH, Steinman L, Lin JC: IL-7 promotes $\mathrm{T}(\mathrm{H}) 1$ development and serum IL-7 predicts clinical response to interferon-beta in multiple sclerosis. Sci Trans/ Med 2011, 3:93ra68.

37. Vaknin-Dembinsky A, Brass SD, Gandhi R, Weiner HL: Membrane bound IL15 is increased on CD14 monocytes in early stages of MS. Neuroimmunol 2008, 195:135-139.

38. Gomez-Nicola D, Spagnolo A, Guaza C, Nieto-Sampedro M: Aggravated experimental autoimmune encephalomyelitis in IL-15 knockout mice. Exp Neurol 2010, 222:235-242.

39. Selmaj K, Raine CS, Cannella B, Brosnan CF: Identification of lymphotoxin and tumor necrosis factor in multiple sclerosis lesions. J Clin Invest 1991, 87:949-954

40. Matusevicius D, Navikas V, Soderstrom M, Xiao BG, Haglund M, Fredrikson S, Link H: Multiple sclerosis: the proinflammatory cytokines lymphotoxinalpha and tumour necrosis factor-alpha are upregulated in cerebrospinal fluid mononuclear cells. J Neuroimmunol 1996, 66:115-123.

41. Buckle GJ, Hollsberg P, Hafler DA: Activated CD8+ T cells in secondary progressive MS secrete lymphotoxin. Neurology 2003, 60:702-705.

42. Aloisi F, Pujol-Borrell R: Lymphoid neogenesis in chronic inflammatory diseases. Nat Rev Immunol 2006, 6:205-217.

43. Bar-Or A, Fawaz L, Fan B, Darlington PJ, Rieger A, Ghorayeb C, Calabresi PA, Waubant E, Hauser SL, Zhang J, Smith CH: Abnormal B-cell cytokine responses a trigger of T-cell-mediated disease in MS? Ann Neurol 2010, 67:452-461.

44. Sellebjerg F, Jensen J, Ryder LP: Costimulatory CD80 (B7-1) and CD86 (B7-2) on cerebrospinal fluid cells in multiple sclerosis. J Neuroimmunol 1998, 84:179-187.
45. Sellebjerg F, Jensen J, Jensen CV, Wiik A: Expansion of CD5 - B cells in multiple sclerosis correlates with CD80 (B7-1) expression. Scand J Immunol 2002, 56:101-107.

doi:10.1186/1742-2094-9-215

Cite this article as: Romme Christensen et al:: Cellular sources of dysregulated cytokines in relapsing-remitting multiple sclerosis. Journal of Neuroinflammation 2012 9:215.

\section{Submit your next manuscript to BioMed Central and take full advantage of:}

- Convenient online submission

- Thorough peer review

- No space constraints or color figure charges

- Immediate publication on acceptance

- Inclusion in PubMed, CAS, Scopus and Google Scholar

- Research which is freely available for redistribution

Submit your manuscript at www.biomedcentral.com/submit
C) BioMed Central 